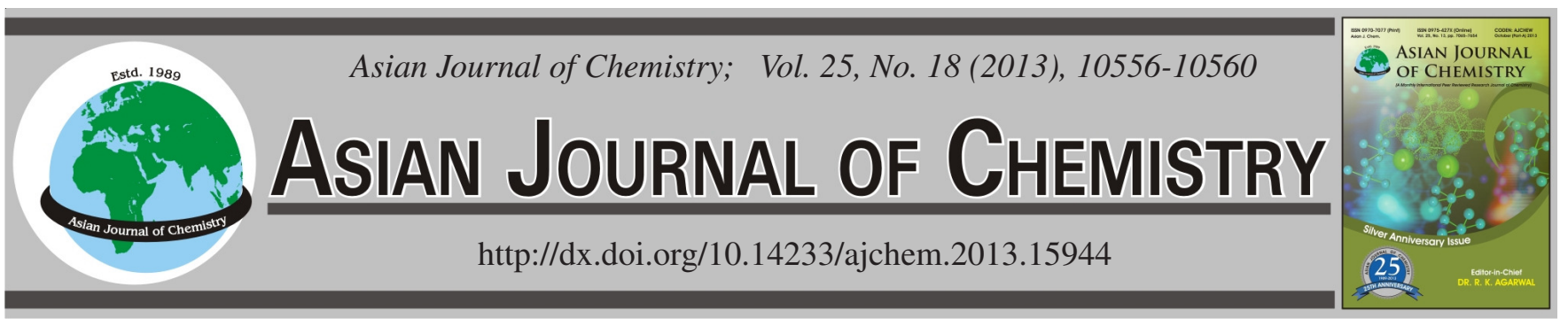

\title{
Dissolution Kinetics of Smithsonite in Sulfamic Acid Solution
}

\author{
Dan-Dan Wu ${ }^{1}$, Shu-Ming Wen ${ }^{1, *}$, Jing Yang ${ }^{2}$, JiU-Shuai Deng ${ }^{1, *}$ and Li Jiang ${ }^{3}$
}

${ }^{1}$ Faculty of Land Resource Engineering, Kunming University of Science and Technology, Kunming 650093, P.R. China

${ }^{2}$ Kunming Vocational and Technical College of Industry, Anning 650302, P.R. China

${ }^{3}$ Office of Academic Affairs, Kunming Metallurgy College, Kunming 650093, P.R. China

*Corresponding authors: E-mail: shmwen@126.com; dengshuai689@163.com

(Received: 21 June 2013;

Accepted: 26 November 2013)

AJC-14446

This study investigated the dissolution kinetics of smithsonite by using sulfamic acid solution as an alternative leaching agent. Moreover,
the effects of certain experimental parameters on the dissolution of smithsonite were investigated using a kinetic model. The dissolution
rate was found to increase with increasing solution temperature, acid concentration and stirring speed, as well as with decreasing particle
size. Moreover, the dissolution rate can be controlled by the shrinking core model for surface chemical reactions. The activation energy of
the dissolution process was determined to be $42.86 \mathrm{~kJ} / \mathrm{mol}$. The results indicated that sulfamic acid solution could be used as a leaching
agent for zinc extraction in smithsonite.

Key Words: Kinetics, Dissolution, Smithsonite, Sulfamic acid.

\section{INTRODUCTION}

Zinc is generally produced from zinc sulfide ores because sulfides are easier to separate from gangue minerals and easier to concentrate via conventional flotation techniques. However, sulphide ores-the primary source of zinc-are becoming depleted. Thus, oxide zinc minerals, such as zincite $(\mathrm{ZnO})$, smithsonite $\left(\mathrm{ZnCO}_{3}\right)$, willemite $\left(\mathrm{Zn}_{2} \mathrm{SiO}_{4}\right)$, hemimorphite $\left[\mathrm{Zn}_{4} \mathrm{Si}_{2} \mathrm{O}_{4}(\mathrm{OH})_{2} \cdot \mathrm{H}_{2} \mathrm{O}\right]$ and hydrozincite $\left[\mathrm{Zn}_{5}\left(\mathrm{CO}_{3}\right)_{2}(\mathrm{OH})_{6}\right]$ have recently become important sources of zinc ores ${ }^{1-3}$.

A large amount of research has been conducted on the treatment of zinc oxide ores via the hydrometallurgical method. In particular, the leaching kinetics of hemimorphite and willemite has been studied extensively ${ }^{4}$. On the other hand, only few studies investigated the leaching of smithsonite ore. These studies used inorganic acids as leaching reagents ${ }^{5-9}$. Organic acids have been used as leaching reagents in recent years $^{10-13}$.

Previous studies discussed the dissolution kinetics of smithsonite ore in ammonium chloride solution, describing the effects of reaction temperature, ammonium chloride concentration, ore particle size and stirring speed on zinc dissolution rate. The results of these studies demonstrated that the zinc leaching of $c a .91 .2 \%$ by using $84-110 \mathrm{~mm}$ ore particle size at a reaction temperature of $90{ }^{\circ} \mathrm{C}$ for a 240 min reaction time with $5 \mathrm{~mol} / \mathrm{L}$ ammonium chloride. The solid/liquid ratio was maintained at $1: 10 \mathrm{~g} / \mathrm{mL}$. The leaching kinetics indicated that both the chemical reaction at the new particle surface and the diffusion through inert particle pores control the dissolution rate. This process was found to have apparent activation energy of $21.3 \mathrm{~kJ} / \mathrm{mol}^{14}$.

Previous studies have investigated the dissolution kinetics of smithsonite ore in hydrochloric acid solution with inorganic acids as leach reagents. The order of the reaction with respect to $\mathrm{HCl}$ concentration, solid-to-liquid ratio and particle size were found to be $0.70,-0.76$ and -0.95 , respectively. In the current study, the optimum leaching conditions for the smithsonite concentrate were found to be $1.5 \mathrm{M} \mathrm{HCl}, 45^{\circ} \mathrm{C},-180+$ $150 \mu \mathrm{m}$ and $25 \mathrm{~g} / \mathrm{L}$ solid-to-liquid (S/L) ratio at $500 \mathrm{rpm}$, which corresponds to more than $95 \%$ zinc extraction. The activation energy of the process was calculated to be $59.58 \mathrm{~kJ} / \mathrm{mol}^{15}$.

Hursit et al. ${ }^{10}$ used organic acids as leaching reagents investigated the dissolution kinetics of smithsonite ore in aqueous gluconic acid solutions in a batch reactor based on certain parameters, such as temperature, acid concentration, particle size and stirring speed. The experimental data complied with the shrinking core model. Stirring speed was found to have no effect on dissolution rate, which is controlled by surface chemical reactions. The activation energy of the process was found to be $47.92 \mathrm{~kJ} / \mathrm{mol}^{10}$.

The current study aims to investigate the dissolution kinetics of smithsonite by using sulfamic acid as a leaching agent and consequently optimize the smithsonite leaching conditions. Moreover, the effects of certain parameters, such 
as temperature, acid concentration, particle size and stirring speed, on the zinc extraction were investigated and the leaching conditions were optimized. A corresponding chemical reaction control model was found to suitably explain the relationship between reaction time and the fraction of zinc leached. Finally, the apparent activation energy of the process was determined.

\section{EXPERIMENTAL}

The pure smithsonite sample was obtained from Yunnan Province in China. The sample was crushed, ground and then sieved with standard test sieves to obtain the desired particle size fractions. The XRD experiments were performed using a Japan Science D/max-R diffractometer apparatus with $\mathrm{CuK}_{\alpha}$ radiation $(\lambda=1.5406 \AA)$ at an operating voltage of $40 \mathrm{kV}$ and a current of $40 \mathrm{~mA}$. The diffraction angle $(2 \theta)$ was scanned from $10-90^{\circ}$. The XRD pattern and the chemical composition of the smithsonite are shown in Fig. 1 and Table-1, respectively. Fig. 1 shows the results of the X-ray analysis, which indicates that the samples consisted of smithsonite and quartz.

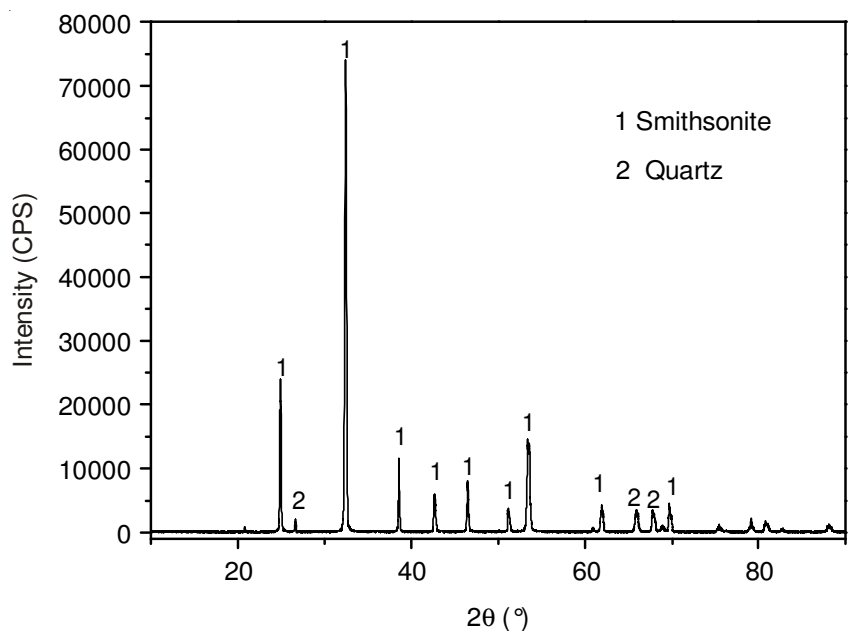

Fig. 1. X-Ray diffraction pattern of the pure smithsonite sample

\begin{tabular}{lccccccc}
\multicolumn{7}{c}{ TABLE-1 } \\
\multicolumn{7}{c}{ CHEMICAL COMPOSITION OF } \\
\\
THE PURE SMITHSONITE SAMPLES \\
\hline Element & $\mathrm{Zn}$ & $\mathrm{Fe}$ & $\mathrm{CaO}$ & $\mathrm{Al}_{2} \mathrm{O}_{3}$ & $\mathrm{~Pb}$ & $\mathrm{Cd}$ & $\mathrm{SiO}_{2}$ \\
\hline Content $(\%)$ & 49.46 & 0.4 & 0.59 & 0.50 & 0.67 & 0.46 & 1.74 \\
\hline
\end{tabular}

Procedure: The dissolution process was conducted in a $1000 \mathrm{~mL}$, three-neck flask batch reactor, which was heated using a thermostat to keep the reactor contents at constant temperature during the reaction. The reactor was equipped with a digitally controlled mechanical stirrer, a thermometer for temperature control and a condenser to prevent material loss via evaporation. Typically, $10 \mathrm{~g}$ of the solid was added into $1000 \mathrm{~mL}$ of the freshly prepared solution at the desired concentration and then $5 \mathrm{~mL}$ of the samples were taken periodically for analysis. The zinc extraction was determined by analyzing the solution for zinc content via inductively coupled plasma-atomic emission spectroscopy (ICP-AES).

\section{RESULTS AND DISCUSSION}

The reaction between smithsonite and sulfamic acid can be expressed as follows:

$$
\begin{gathered}
2 \mathrm{NH}_{3} \mathrm{SO}_{3} \rightarrow 2 \mathrm{H}^{+}{ }_{(\mathrm{aq})}+2 \mathrm{NH}_{2} \mathrm{SO}_{3}^{-}{ }_{(\mathrm{aq})} \\
\mathrm{ZnCO}_{3(\mathrm{~s})}+2 \mathrm{H}^{+}{ }_{(\mathrm{aq})} \rightarrow \mathrm{Zn}^{2+}{ }_{(\mathrm{aq})}+\mathrm{CO}_{2(\mathrm{~g})}+\mathrm{H}_{2} \mathrm{O}_{(\mathrm{l})} \\
\mathrm{ZnCO}_{3(\mathrm{~s})}+2 \mathrm{NH}_{3} \mathrm{SO}_{3(\mathrm{aq})} \rightarrow \mathrm{Zn^{2+ }}{ }_{(\mathrm{aq})}+2 \mathrm{NH}_{2} \mathrm{SO}_{3}^{-}(\mathrm{aq}) \\
+\mathrm{CO}_{2(\mathrm{~g})}+\mathrm{H}_{2} \mathrm{O}_{(\mathrm{l})}
\end{gathered}
$$

Effect of temperature: A series of tests, each lasting for $1 \mathrm{~h}$, was conducted to determine the effect of temperature on zinc extraction. The tests for the $-96+75 \mu \mathrm{m}$ particles were conducted at a temperature ranging from 20 to $70^{\circ} \mathrm{C}, 0.5 \mathrm{~mol} / \mathrm{L}$ of sulfamic acid, 1:100 $\mathrm{g} / \mathrm{mL}$ solid/liquid ratio and stirring speed of $800 \mathrm{rpm}$.

Fig. 2 shows the results of the experiments conducted to determine the effect of temperature. Under the experimental conditions mentioned above, the extraction rate of zinc from smithsonite ore increased considerably with increasing temperature. Zinc extraction increased from 28.99 to $98.95 \%$ when the temperature was increased from 20 to $70{ }^{\circ} \mathrm{C}$.

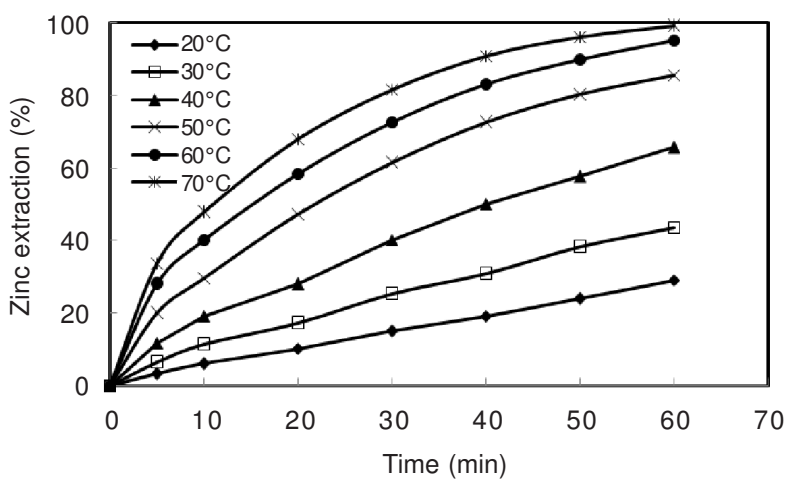

Fig. 2. Effect of temperature on smithsonite dissolution

Effect of sulfamic acid concentration: Experiments were conducted on five different sulfamic acid concentrations ranging from 0.125 to $0.675 \mathrm{~mol} / \mathrm{L}$ to investigate the effect of sulfamic acid concentration on the dissolution rate. The procedure for the $-96+75 \mu \mathrm{m}$ particles was conducted at $60{ }^{\circ} \mathrm{C}$, stirring speed of $800 \mathrm{rpm}$ and $1: 100 \mathrm{~g} / \mathrm{mL}$ solid/liquid ratio. Fig. 3 shows the variations in the leaching rate of various sulfamic acid concentrations. The zinc leaching rate increased when the sulfamic acid concentration increased from 0.125 to 0.675 $\mathrm{mol} / \mathrm{L}$. Experimental results show that 77.48 and $95.13 \%$ of zinc were extracted from the sulfamic acid concentrations of 0.125 and $0.5 \mathrm{~mol} / \mathrm{L}$, respectively. The extent of extraction slightly increased $(95.13 \%$ at $0.5 \mathrm{~mol} / \mathrm{L}$ and $98.58 \%$ at 0.675 $\mathrm{mol} / \mathrm{L}$ ) when the sulfamic acid concentration was further increased to more than $0.5 \mathrm{~mol} / \mathrm{L}$.

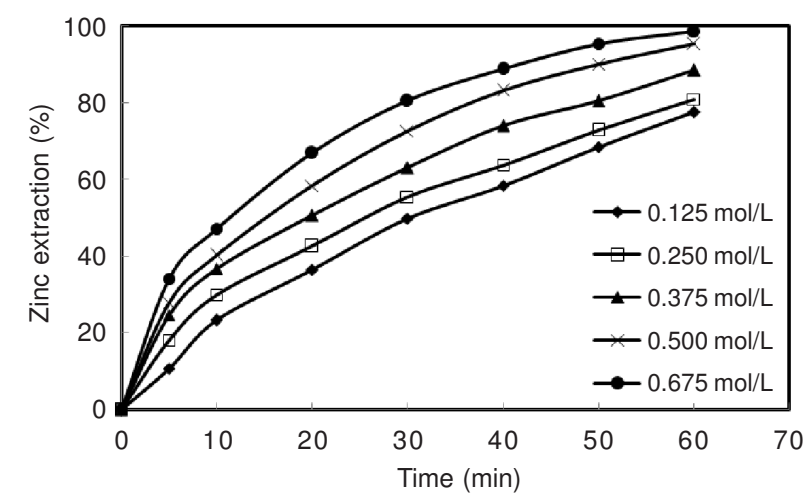

Fig. 3. Effect of sulfamic acid concentration on smithsonite dissolution 
Effect of particle size: Five different particle sizes $(-425$ $+250,-250+150,-150+96,-96+75$ and $-75+45 \mu \mathrm{m})$ were used in the experiments. The experiments were conducted at $0.5 \mathrm{~mol} / \mathrm{L}$ sulfamic acid concentration, $60^{\circ} \mathrm{C}, 1: 100 \mathrm{~g} / \mathrm{mL}$ solid/ liquid ratio and $800 \mathrm{rpm}$ stirring speed. The zinc dissolution rate increased with smaller particle size (Fig. 4). The contact area of the particles with the fluid increased with smaller particle size. These results show that particle size had a significant effect on zinc dissolution. Zinc extraction reached $77.93 \%$ at the particle size of $-425+250 \mu \mathrm{m}$ and then increased to $98.45 \%$ at the particle size of $-75+45 \mu \mathrm{m}$ after $1 \mathrm{~h}$.

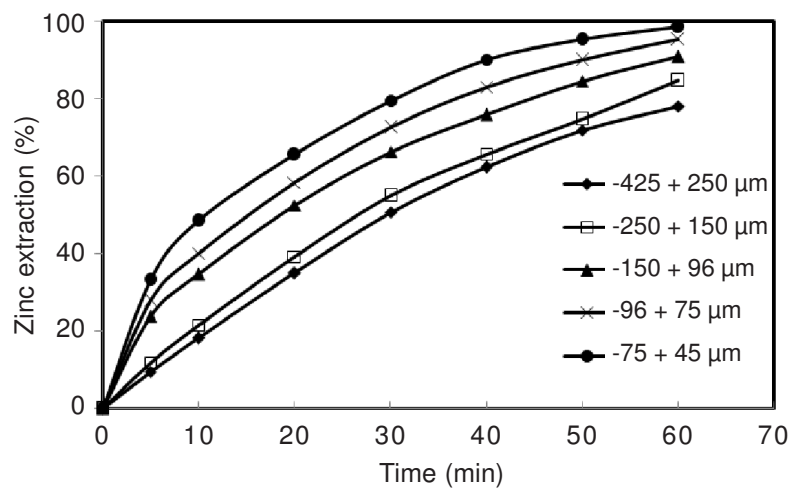

Fig. 4. Effect of particle size on smithsonite dissolution

Effect of stirring speed: Experiments on five different agitation rates ranging from 200 to $1000 \mathrm{rpm}$ were conducted to determine the effect of stirring speed on the leaching of smithsonite ore. In these experiments, the reaction temperature, sulfamic acid concentration, particle size and solid-to-liquid ratio were kept constant at $60^{\circ} \mathrm{C}, 0.5 \mathrm{~mol} / \mathrm{L},-96+75 \mu \mathrm{m}$ and $1: 100 \mathrm{~g} / \mathrm{mL}$, respectively. Fig. 5 shows the results of the experiments, wherein the extent of zinc leaching increased slightly with increasing stirring speed. The zinc leaching percentage was $84.96 \%$ at a stirring speed of $200 \mathrm{rpm}$ and then increased to $98.81 \%$ when the stirring speed was increased to 1000 rpm.

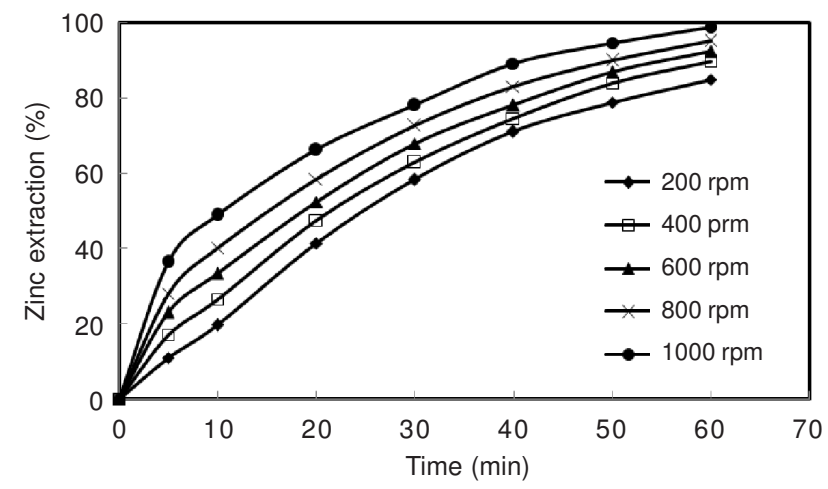

Fig. 5. Effect of stirring speed on smithsonite dissolution

Kinetics study: Smithsonite leaching can be explained using the following shrinking core model:

$$
\text { aAfluid }+ \text { bB solid } \rightarrow \text { Product }
$$

If the reaction rate is controlled by diffusion through a product layer, then the integrated rate equation can be expressed as follows ${ }^{16,17}$ :

$$
1-\frac{2}{3} \mathrm{X}-(1-\mathrm{X})^{2 / 3}=\mathrm{k}_{\mathrm{d}} \mathrm{t}
$$

If the reaction is controlled by a surface chemical reaction, then the integrated rate equation of this step can be written as follows ${ }^{7,18}$ :

$$
1-(1-\mathrm{X})^{1 / 3}=\mathrm{k}_{\mathrm{r}} \mathrm{t}
$$

where $\mathrm{X}$ is the solid particle conversion fraction, $\mathrm{k}_{\mathrm{d}}$ is the apparent rate constant for diffusion through the product layer, $\mathrm{k}_{\mathrm{r}}$ is the apparent rate constant for the surface chemical reaction and $\mathrm{t}$ is the reaction time.

The eqn. 5 versus time was plotted for temperature, solution concentration, particle size and stirring speed to test the validity of the model in eqn. 5. Figs. 6-9 show the graphs obtained. As can be seen in Figs. 6-9, the kinetic model in eqn. 5 appropriately represents the leaching process.

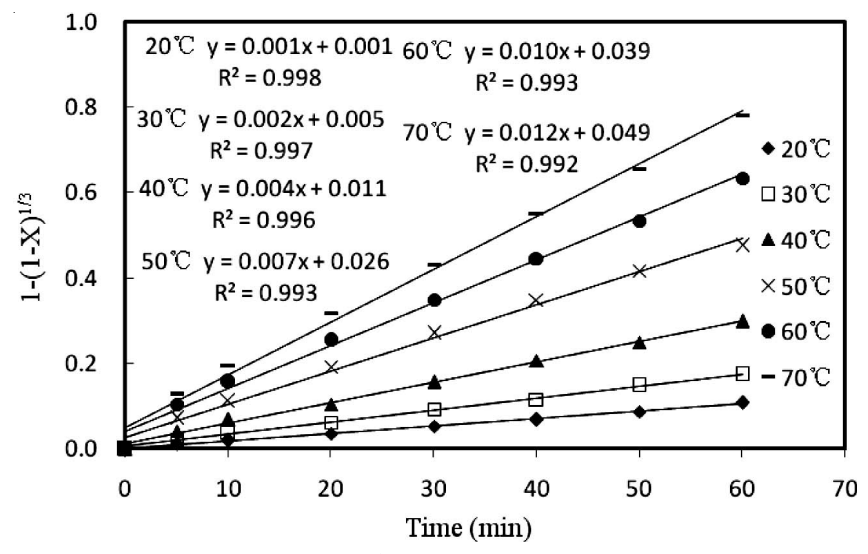

Fig. 6. Plot of 1-(1-X) $)^{1 / 3}$ versus $\mathrm{t}$ at various temperatures

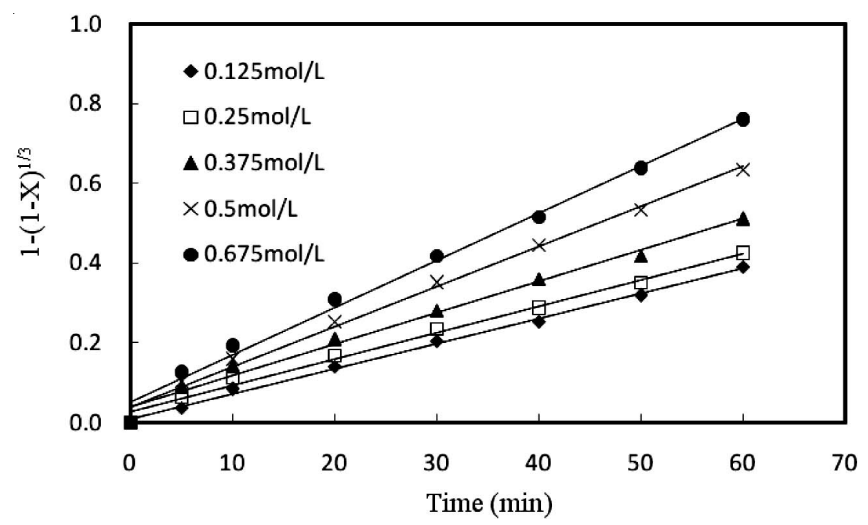

Fig. 7. Plot of $1-(1-\mathrm{X})^{1 / 3}$ versus $\mathrm{t}$ at various sulfamic acid concentrations

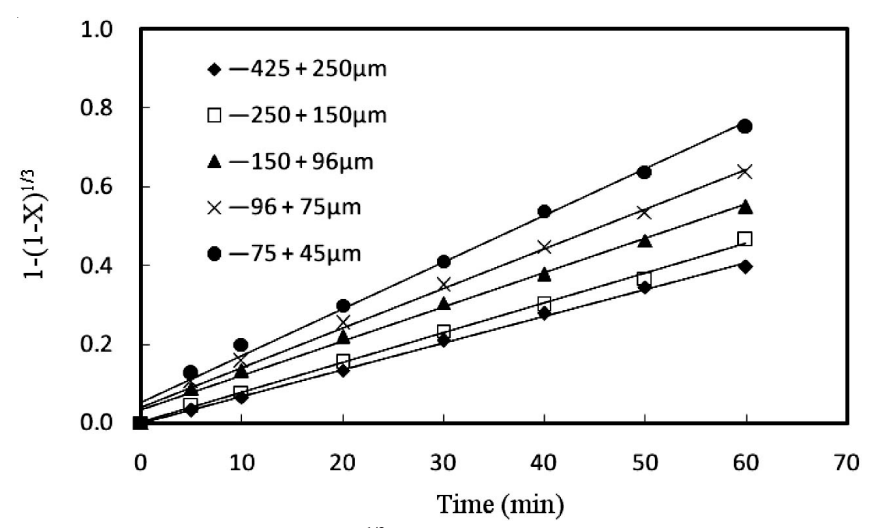

Fig. 8. Plot of 1-(1-X) $)^{1 / 3}$ versus $\mathrm{t}$ for various particle sizes 


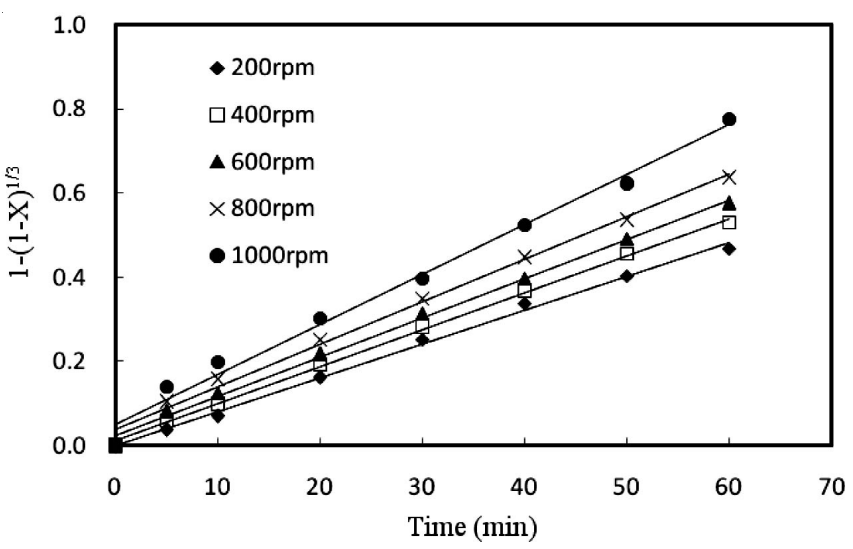

Fig. 9. Plot of 1-(1-X) $)^{1 / 3}$ versus t at various stirring speeds

Fig. 10 shows the Arrhenius plot of the leaching process. The activation energy was calculated to be $\mathrm{E}=42.86 \mathrm{~kJ} / \mathrm{mol}$. The Arrhenius plot was consistent with the rate limitation steps described above.

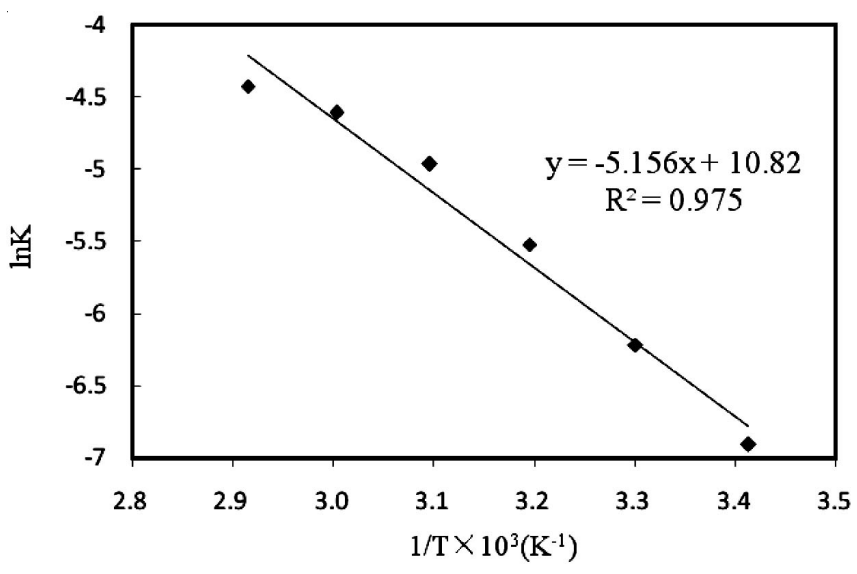

Fig. 10. Arrhenius plot of the smithsonite dissolution

Thus, the equation representing the kinetics of the leaching process can be expressed as follows:

$$
1-(1-\mathrm{X})^{1 / 3}=\left[\mathrm{k}_{0} \cdot(\mathrm{C})^{\alpha} \cdot\left(\mathrm{r}_{0}\right)^{\beta} \cdot(\mathrm{SS})^{\gamma} \exp (-\mathrm{E} / \mathrm{RT})\right] \mathrm{t}
$$

where $\mathrm{C}, \mathrm{r}_{0}, \mathrm{SS}, \mathrm{E}, \mathrm{R}$ and T represent the concentration, particle size, stirring speed, activation energy, universal gas constant and temperature, respectively. The constants $\alpha, \beta$ and $\gamma$ are the reaction order of the related parameters and $\mathrm{k}_{0}$ is the frequency or pre-exponential factor.

$\alpha, \beta$ and $\gamma$ were determined to be $0.488,-0.361$ and 3.509 , as shown in Figs. 11-13, respectively.

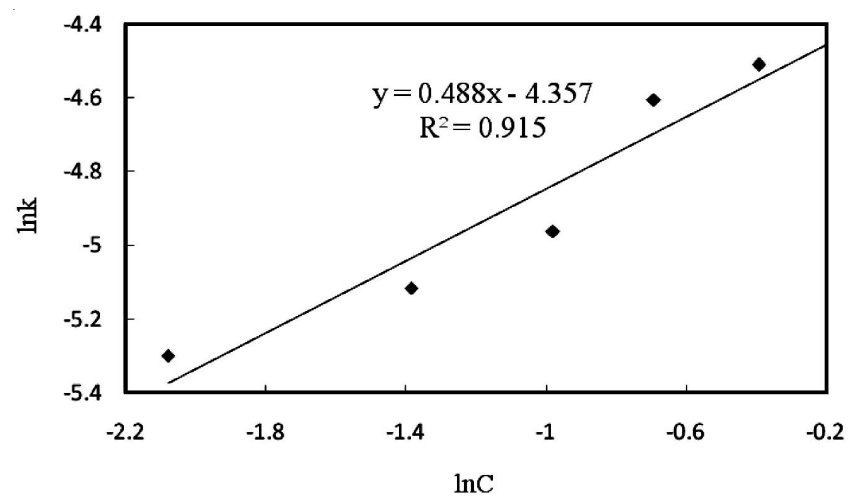

Fig. 11. Plot of $\ln \mathrm{k}$ versus sulfamic acid concentration

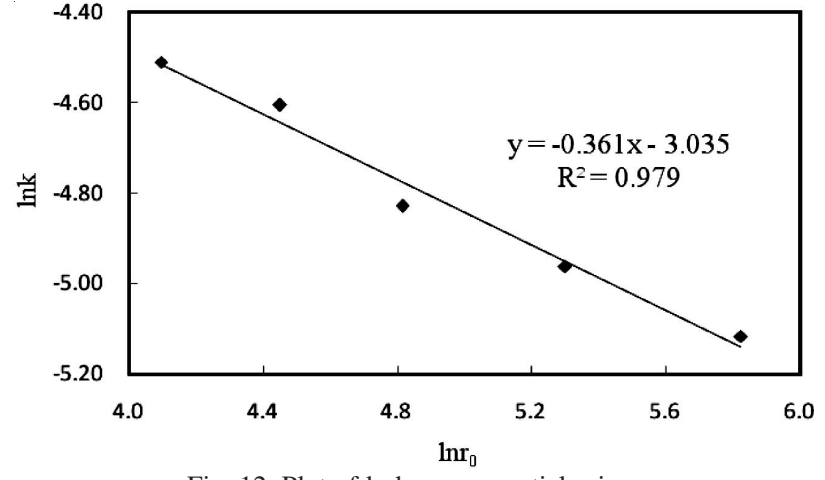

Fig. 12. Plot of $\ln \mathrm{k}$ versus particle sizes

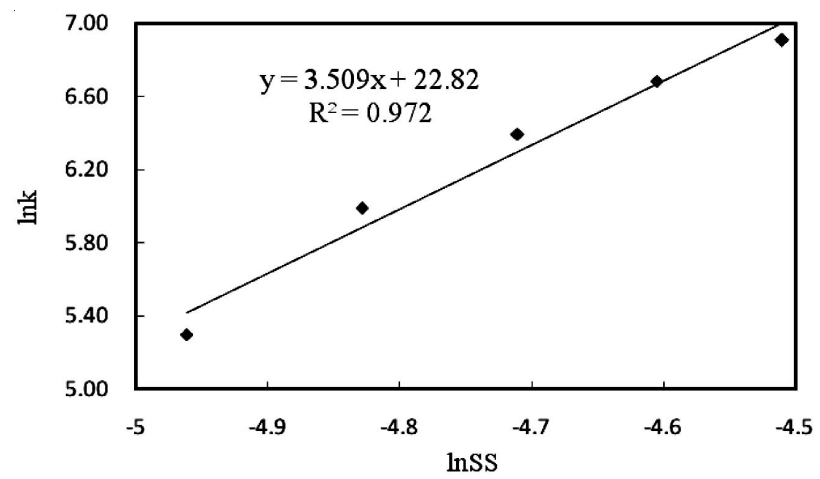

Fig. 13. Plot of $\ln \mathrm{k}$ versus stirring speed

Thus, the leaching of smithsonite ore can be described as follows:

$$
1-(1-\mathrm{X})^{1 / 3}=\left[\mathrm{k}_{0} \cdot(\mathrm{C})^{0.488} \cdot\left(\mathrm{r}_{0}\right)^{-0.361} \cdot(\mathrm{SS})^{3.509} \exp (-42.86 / \mathrm{RT})\right] \mathrm{t}
$$

\section{Conclusion}

This study investigated the dissolution kinetics of smithsonite in sulfamic acid solutions as well as the factors affecting the kinetics. The dissolution kinetics of smithsonite concentrate in the sulfamic acid solutions was found to be controlled by the shrinking core model for surface chemical reactions. The activation energy was calculated to be $42.86 \mathrm{~kJ} / \mathrm{mol}$ at the temperature ranging from 20 to $70{ }^{\circ} \mathrm{C}$. The dissolution rate can be expressed by eqn. 7 . The order of the reaction with respect to sulfamic acid concentration, particle size and stirring speed was found to be $0.488,-0.361$ and 3.509 , respectively. The dissolution rate increased with decreasing particle size. The results indicate that sulfamic acid can easily dissolve zinc in smithsonite ores. The optimum leaching conditions were found to be temperature of $70^{\circ} \mathrm{C}$, sulfamic acid concentration of $0.675 \mathrm{~mol} / \mathrm{L}$, particle size of $-75+45 \mu \mathrm{m}$ and stirring speed of $1000 \mathrm{rpm}$. A reaction time of $1 \mathrm{~h}$ was found to be sufficient to exceed $98 \%$ zinc extraction.

\section{ACKNOWLEDGEMENTS}

This research project was supported by the Key Program of the National Natural Science Foundation of China (u0837602 \& KKGE201121001), Natural Science Foundation of Yunnan Province Education Department (2012J085), Excellent Doctoral Dissertation Foundation of Kunming University of Science and Technology (No. 41118011) and the Analysis and Testing Foundation of Kunming University of Science and Technology (No. 2011464). 


\section{REFERENCES}

1. S. Espiari, F. Rashchi and S.K. Sadrnezhaad, Hydrometallurgy, 82, 54 (2006).

2. S.H. Hosseini and E. Forssberg, Miner. Metallur. Process., 23, 87 (2006).

3. Z.L. Yin, Z.Y. Din, H.P. Hu, K. Liu and Q.Y. Chen, Hydrometallurgy, 103, 215 (2010)

4. F.M.F. Santos, P.S. Pina, R. Porcaro, V.A. Oliveira, C.A. Silva and V.A. Leão, Hydrometallurgy, 102, 43 (2010).

5. E.A. Abdel-Aal, Hydrometallurgy, 55, 247 (2000).

6. M.M. Antonijevic, M. Dimitrijevic and Z. Jankovic, Hydrometallurgy, 46, 71 (1997).

7. Z. Ekinci, S. Colak, A. Cakici and H. Sarac, Miner. Eng., 11, 279 (1998).

8. B. Liang, C. Li, C.G. Zhang and Y.K. Zhang, Hydrometallurgy, 76, 173 (2005)

9. P. Raschman and A. Fedorockova, Hydrometallurgy, 71, 403 (2004).
10. M. Hursit, O. Lacin and H. Sarac, J. Taiwan Inst. Chem. Eng., 40, 6 (2009).

11. F. Bakan, O. Lacin, B. Bayrak and S. Hanifi, Int. J. Miner. Process., 80, 27 (2006)

12. B. Bayrak, O. Lacin, F. Bakan and H. Sarac, Chem. Eng. J., 117, 109 (2006).

13. F. Demir, O. Lacin and B. Donmez, Ind. Eng. Chem. Res., 45, 1307 (2006).

14. S.H. Ju, M.T. Tang, S.H. Yang and Y.N. Li, Hydrometallurgy, 80, 67 (2005).

15. N. Dhawan, M.S. Safarzadeh and M. Birincid, Metallurgy Nonferr. Met., 52, 209 (2011).

16. A.A. Baba and F.A. Adekola, Hydrometallurgy, 101, 69 (2010).

17. X.L. Sun, B.Z. Chen, X.Y. Yang and Y.Y. Liu, J. Central South Univ. Technol., 16, 936 (2009).

18. P.K. Jena, O. Barbosa-Filho and I.C. Vasconcelos, Hydrometallurgy, 52, 111 (1999). 